\title{
Prevalence of vaccine and non-vaccine human papillomavirus types among women in Accra and Kumasi, Ghana: a cross-sectional study
}

Oksana Debrah ${ }^{1,5^{*}}$, Francis Agyemang-Yeboah², Emmanuel Timmy Donkoh ${ }^{3}$ and Richard Harry Asmah ${ }^{4}$

\begin{abstract}
Background: Human Papillomavirus (HPV) infection is the main etiological factor for pre-invasive and invasive cervical cancer. HPV type-specific vaccination is being widely recommended to control the burden of disease, but the genotype-specific distribution of HPV may vary in different countries. The aim of the study was to determine the prevalence and distribution of HPV genotypes among women attending reproductive health services in Ghana, their associated risk factors, and to assess the potential coverage of identified HPV genotypes by three licensed vaccines among these women.
\end{abstract}

Method: Women presenting for reproductive health services in two regional hospitals in Accra and Kumasi from October 2014 to March 2015 were conveniently recruited into the study $(n=317)$. HPV-DNA detection and genotype identification were carried out by a nested multiplex PCR assay that combines degenerate E6/E7 consensus primers and type-specific primers for the detection and typing of eighteen HPV genotypes. Cytology was performed to screen women for cervical cancer lesions. Risk factors for HPV infection were analyzed by logistic regression. Statistical significance was accepted for $p<0.05$.

Results: The age of study participants ranged from 21 to 76 years. Among women positive for HPV, 35.0\% were infected with high-risk HPV, $14.5 \%$ with probable high-risk HPV, and $17.0 \%$ with low-risk HPV. The prevalence of HPV $16 / 18$ was $8.2 \%$, HPV 6/11/16/18 was $9.1 \%$ and HPV 6/11/16/18/31/33/45/52/58 was $28.4 \%$. The most prevalent among HR-HPV were types $52(18.3 \%)$ and 58 (8.8\%). HPV positivity may be associated with educational background $(p<0.001)$, age at first pregnancy $(p=0.028)$, and age at coitarche $(p=0.016)$.

Conclusions: Our study revealed a high prevalence of HR-HPV infection among women. The high prevalence of HR HPV indicates that multivalent vaccines will be useful for controlling HPV burden in general population contexts. The distribution of HPVs in this population suggests that of the three currently available vaccines the nonavalent vaccine, which protects against seven HPV types in addition to HPV 16 and 18, has the highest coverage of HPV infections among Ghanaian women. Healthcare officials planning to reduce the transmission of HPV and cervical cancer must consider the coverage of the nonavalent vaccine as an advantage.

Keywords: Human papillomavirus, Genotype distribution, HPV vaccine, Ghana

\footnotetext{
${ }^{*}$ Correspondence: oksanadeb@yahoo.com

${ }^{1}$ Institutional Care Division, Ghana Health Service Headquarters, Stadium

Post Office, Post Office Box SD 329, Accra, Ghana

Full list of author information is available at the end of the article
} original author(s) and the source, provide a link to the Creative Commons licence, and indicate if changes were made. The images or other third party material in this article are included in the article's Creative Commons licence, unless indicated otherwise in a credit line to the material. If material is not included in the article's Creative Commons licence and your intended use is not permitted by statutory regulation or exceeds the permitted use, you will need to obtain permission directly from the copyright holder. To view a copy of this licence, visit http://creativecommons.org/licenses/by/4.0/. The Creative Commons Public Domain Dedication waiver (http://creativeco mmons.org/publicdomain/zero/1.0/) applies to the data made available in this article, unless otherwise stated in a credit line to the data. 


\section{Introduction}

Human papillomavirus (HPV) infection is the most common sexually transmitted viral infection worldwide [1]. Over 200 HPV types have been identified and have been completely sequenced [2]. Genital HPV types are classified as high risk (HR), probable high risk (PHR) or low risk (LR) according to the degree or likelihood associated with developing cervical cancer [1,2]. Approximately 50 genotypes are known to be oncogenic or HR and are correlated with invasive cervical cancer [3]. Among the 15 most common types known to be carcinogenic, HPV16 and HPV18 are responsible for approximately $70 \%$ of cervical cancer worldwide $[4,5]$. Other oncogenic HPV types, including HPV $31,33,45,52$, and 58 , are estimated to be responsible for another $18 \%$ of cervical cancers [6].

In Ghana, cervical cancer is ranked as the second most common cancer with an estimated incidence of 27.4 per 100,000 women [7, 8]. Around 2797 women are diagnosed yearly and approximately 1699 deaths occur from cervical cancer [7, 8]. The World Health Organization (WHO) predicts that there will be 5000 new cases of cervical cancer and 3361 cervical cancer deaths will occur annually in Ghana by 2025 [9].

HPV vaccination for young girls and cervical screening programs for older women can be an effective strategy to prevent cervical cancer $[10,11]$. Cervical screening programs, such as cervical cytology and visual inspection with acetic acid (VIA), are available but not mandatory in Ghana. The cervical screening programs are only effective on cervical cancer mortality, if a high proportion of women participate [12]. Moreover, it has been difficult to implement screening programs for cervical cancer in Ghana as well as in most sub-Saharan African countries, partly due to competing health needs such as HIV, malaria, tuberculosis and malnutrition [13, 14].

Currently, three HPV-vaccines have been approved: quadrivalent Gardasil $^{\circledR}$, Cervarix ${ }^{\circledR}$, and a nonavelent Gardasil $^{\circledR}$ consisting of type-specific HPV L1 virus-like particles (VLPs) that induce type-restricted protection [15-17]. All three vaccines prevent HPV-16 and HPV-18 infection. Quadrivalent-Gardasil ${ }^{\circledR}$ also protects against HPV-6 and HPV-11 whereas the nonavalent Gardasi ${ }^{\circledR}$ targets an additional five HPV types (HPV-31, 33, 45, 52, and 58) [18]. These vaccines may also have some crossprotection against other less common HR-HPV types [19, 20]. HPV-vaccination is documented to be safe, immunogenic, and associated with decreased HPV infection rates and lowered risk of HPV related diseases [21-23].

In Ghana, the quadrivalent-Gardasil ${ }^{\circledR}$ vaccine was piloted into the school-based vaccination program for 6000 girls aged years, in four districts in the Northern and Greater Accra Regions with support from the GAVI Alliance in November 2013 [24]. Meanwhile, the vaccine is available to the public for vaccination at a cost of approximately USD 50 per dose, potentially rising to USD 150 for three doses [25]. In spite of their availability for almost a decade, the uptake of HPV vaccines in Ghana has been poor. A number of reasons such as exclusion from services covered by universal health insurance and the low patronage of reproductive health services by adolescent girls may be cited [25-27]. However, the cost of HPV vaccines is a well-known barrier to vaccine accessibility in Sub-Saharan Africa and more innovative pricing solutions are constantly sought $[25,28,29]$. The large-scale deployment of vaccines with a broad coverage of common HPV types in a single-dose regimen could represent a sustainable, cost-effective, preventive strategy and potentially increase uptake of vaccination [30]. However, very few studies on HPV types not targeted by the present HPV-vaccines among Ghanaian women are available. The aim of our study was to determine the prevalence and distribution of HPV genotypes among Ghanaian women, their associated risk factors and to assess the potential coverage of identified HPV genotypes by available licensed vaccines.

\section{Materials and methods}

\section{Study design, population and sampling technique}

Between October, 2014 and March, 2015, women presenting to the Cervicare/Reproductive Health Clinics at the Kumasi South Regional Hospital in Kumasi, Ashanti Region and Greater Accra Regional Hospital in Accra, Greater Accra Region, Ghana, for reproductive counselling, routine family planning, visual screening, Pap smear testing and other support services were invited to participate in this hospital-based study. The minimum sample size was determined using the Cochran formula [31] for estimating single population proportions. In a previous study, the prevalence of HPV 16/18 was 5\% [32] and the utilization of reproductive health services was approximately $8 \%$ for women of fertility age (WIFA) in study areas [33]. Based on a confidence level of $95 \%$ $(\mathrm{z}=1.96), 5 \%$ margin of error $(\mathrm{d})$, and $10 \%$ non-response rate, a minimum sample size of 317 was required. The convenient sampling technique was employed to enroll participants. Criteria for exclusion included: pregnancy; $<20$ years-old; actively menstruating on the day of sample collection; history of hysterectomy or conization; history of Pap smear and prior HPV vaccination. Participants were fully informed about the purpose, procedures, risks, and benefits of participating in this study and informed consent was obtained from all subjects.

The study was approved by the Committee on Human Research Publication and Ethics (CHRPE), Kwame Nkrumah University of Science and Technology, School of Medical Sciences (KNUST-SMS) and Komfo Anokye 
Teaching Hospital (KATH) (CHRPE/AP/115/14), Kumasi, Ghana and Ghana Health Service Ethical Review Committee, Research and Development Division (GHSERC: 07/03/2014) in accordance with the revised Helsinki Declaration of 1964 (revised 2000) on ethical principles for medical research involving human subjects.

\section{Data collection}

At enrolment, participants completed a questionnaire and provided data on sexual behavior, reproductive history, contraceptive practice, smoking habits, history of sexually transmitted disease, screening history, and various measures of demographics and socioeconomic status (e.g., occupation, education), cervical cancer screening options and HPV vaccination.

\section{Sample collection and processing}

Two cervical samples (one each for Pap and HPV testing) were collected by trained nurses. Cervical specimens for HPV DNA test were suspended in a proprietary DNA solution (Biomatrica Co., San Diego, USA) for DNA preservation at room temperature until DNA extraction.

For cytological examination, all samples were stained using the modified Papanicolaou technique [34]. Results from cervical cytology specimens were reported according to the 2014 Bethesda Classification System for reporting cervical cytology [35].

\section{Genomic DNA extraction}

Genomic DNA from cervical swabs was extracted using commercial spin-column based QIAamp Mini kit (QIAGEN, Hilden, Germany), according to the manufacturer's instructions. The DNA was aliquoted in duplicate $(25 \mu \mathrm{l}$ each into separate $2 \mathrm{ml}$ Eppendorf tubes) and stored at $-20{ }^{\circ} \mathrm{C}$ until further analysis. The concentration of extracted DNA was determined by spectrophotometry at $260 \mathrm{~nm}$ (Nano-Drop 2000c spectrophotometer, Thermo Fisher Scientific, USA). All samples were pre-screened with the human $\beta$-globin primers $\mathrm{PCO} 3+/ \mathrm{PCO} 4+$ to assess sample integrity [36]. Briefly, for a PCR volume of $25 \mathrm{ml}, 1-4 \mathrm{ml}$ of the DNA lysate and $25 \mathrm{pmol}$ of each human beta-globulin consensus primers $\mathrm{PCO}+$ and PCO4+ (Integrated DNA Technologies, Inc, USA) were used. Purified DNA was used in PCR as templates to amplify target regions.

\section{DNA HPV analysis}

HPV-DNA detection and identification of the genotypes was carried out by nested multiplex PCR (NMPCR) as described by Sotlar et al. [37]. Briefly, a single consensus forward primer (GP-E6-3F) and two consensus back primers (GP-E7-5B and GP-E7-6B) were used for the general primer PCR. The PCR reaction mix of $50 \mu \mathrm{l}$ contained 10X PCR buffer, $2.5 \mathrm{mM} \mathrm{MgCl}_{2} 200 \mu \mathrm{M}$ of each of the four deoxyribonucleoside triphosphates (dNTP), 15 pmols of each E6/E7 consensus primers and 1.25 units of Taq polymerase enzyme (New England Biolabs Inc., UK). Four microlitres $(4 \mu \mathrm{l})$ of DNA extracts was used as template for the amplification reactions. This was carried out using a thermal cycler (Stratagene Robocycler Gradient 96, Roche Molecular System Inc, USA). The cycling parameters for the first round PCR with $\mathrm{E} 63 \mathrm{~F} / \mathrm{E} 75 \mathrm{~B} / \mathrm{E} 76 \mathrm{~B}$ consensus primers were as follows: $94{ }^{\circ} \mathrm{C}$ for $4 \mathrm{~min}$ (initial denaturation), followed by 40 cycles of $94{ }^{\circ} \mathrm{C}$ for $1 \mathrm{~min}$ (denaturation), $40{ }^{\circ} \mathrm{C}$ for $2 \mathrm{~min}$ (annealing), $72{ }^{\circ} \mathrm{C}$ for $2 \mathrm{~min}$ (extension) and a single final elongation step of $72{ }^{\circ} \mathrm{C}$ for $10 \mathrm{~min}$. In the second round PCR, $2 \mu \mathrm{l}$ of first round PCR product, 15 pmols of forward and reverse primers for genotyping were used. Primers for the identification of high-risk genotypes 16 , $18,31,33,35,39,45,51,52,56,58,59$; probable high-risk genotypes 66 and 68, and low-risk genotypes 6/11, 42, 43, and 44 were used in four cocktails, each containing four to five different primer pairs. The other parameters that were used in the first round PCR mix were maintained. However, the cycling parameters were as follows: $94{ }^{\circ} \mathrm{C}$ for 4 min followed by 35 cycles of $94{ }^{\circ} \mathrm{C}$ for $30 \mathrm{~s}, 56{ }^{\circ} \mathrm{C}$ for $30 \mathrm{~s}, 72^{\circ} \mathrm{C}$ for $45 \mathrm{~s}$ and a single final elongation step of $72{ }^{\circ} \mathrm{C}$ for four minutes.

\section{Detection of PCR products}

The amplified products were detected by agarose gel electrophoresis (2\%), containing $0.5 \mu \mathrm{g} / \mathrm{ml} \mathrm{EZ-Vision}{ }^{\circledR}$ Bluelight DNA dye (AMRESCO, LLC USA). Ten microlitres of each sample was added to $2 \mu \mathrm{l}$ of orange G (5X) gel loading dye for the electrophoresis. Hundred base pair DNA molecular weight marker (New England Biolabs Inc., UK) was run alongside the PCR products. The gel was prepared and electrophoresed in $1 \mathrm{X}$ TAE buffer using a mini gel system at $100 \mathrm{~V}$ for one hour. The gels were viewed in a benchtop UV illuminator (UVP, LLC, Upland, CA, USA) and photographed using Canon camera Sx230 HS.

All methods were carried out in accordance with relevant guidelines and regulations.

\section{Statistical analysis}

Data obtained from the questionnaire was checked for accuracy, stored in Microsoft Excel 2010 software (Microsoft Corporation, Redmond Campus, Washington DC, USA) and analyzed using the Statistical Package for Social Scientists (SPSS) version 22. Qualitative variables were described by simple counts and percentages. The confidential interval $(95 \% \mathrm{CI})$ for the prevalence was determined using the Cochran formula [31]. Quantitative variables were represented as mean $\pm \mathrm{SD}$. Any HPV 
infection/overall HPV infection was defined as any or inclusive of all $18 \mathrm{HPV}$ types. HPV genotypes were grouped according to the licensed vaccines: $\mathrm{HPV}-16 / 18$, HPV-6/11/16/18 and HPV-6/11/16/18/31/33/45/52/58. Type-specific reporting on HPV genotypes accounted for each infection independently in women with multiple infections. The distribution of HPV genotypes was summarized using frequency distributions. The relation of HPV genotypes with demographic, gynecological and behavioral variables were examined by logistic regression. A $p$ value $<0.05$ was considered statistically significant.

\section{Results}

\section{Study population characteristics}

In total, complete the consent process and questionnaire. 317 women were screened for HPV genotypes after documenting informed consent and questionnaire administration. Analysis of the study population $(\mathrm{n}=317)$ by sociodemographic characteristics revealed that more than half $(67.8 \%: 215 / 317)$ of the respondents were between ages 25 and 44 years, married or cohabiting (64.7\%: 205/317) (Table 1). Most were economically active (86.8: 275/317) with an educational level described as senior high school and higher (59.3\%: 188/317). Concerning their sexual and reproductive characteristics, most (76.9\%: 244/317) of the respondents were multiparous women who had their first pregnancy after age of 18 years (73.2\%: 232/317) and had their first sexual contact before age 20 years (60.9\%: 193/317).

\section{Overall HPV prevalence and type distribution}

The estimated burden of non-specific HPV infections among women was 43.5\% (95\% CI 37.5-48.6\%) (Table 2). The prevalence of high-risk (HR) HPV genotypes (types $16,18,31,33,35,39,45,51,52,56,58$ and 59 ) was $35.0 \%$ (95\% CI 29.0-40.4\%), low risk-(LR) HPV genotypes (types 6/11, 42, 43 and 44 ) was $17.0 \%$ (95\% CI 12.9 21.2\%), while that of probable high-risk (PHR) HPV genotypes (types 66 and 68 ) was 14.5\% (95\% CI 10.7-18.3\%). The HR HPV group caused the majority of the HPV infections (80.4\% of HPV positive cases), followed by the LR HPV group (39.1\% of HPV positive cases) and PHR HPV group (29.7\% of HPV positive cases).

Among the LR HPV group the most common genotype was HPV-42 (9.5\%, 95\% CI 6.3-12.9) followed by HPV43 (5.4\%, 95\% CI 2.8-0.8.2). HPV type 66 and HPV type 68 (probable high risk types), were detected 7.9\% (95\% CI 5.3-11.1) and 8.2\% (95\% CI 5.7-11.4), respectively. The more prevalent HR types were HPV 52 (18.3\%, 95\% CI 14.2-22.4), HPV 58 (8.8\%, 95\% CI 5.7-12.0), HPV 35 (5.4\%, 95\% CI 2.8-7.9), HPV 16 (4.4\%, 2.2-6.6), HPV 18 (4.1\%, 95\% CI 2.2-6.3) and HPV 45 (4.1\%, 95\% CI
Table 1 Demographic characteristics of study population

\begin{tabular}{|c|c|c|}
\hline Characteristics & Number & Percentage (\%) \\
\hline \multicolumn{3}{|l|}{ Age group (years) } \\
\hline$\leq 25$ & 8 & 2.5 \\
\hline $25-44$ & 215 & 67.8 \\
\hline $45-64$ & 87 & 27.4 \\
\hline$\geq 65$ & 7 & 2.2 \\
\hline \multicolumn{3}{|l|}{ Education } \\
\hline Below SHS & 188 & 59.3 \\
\hline SHS and above & 129 & 40.7 \\
\hline \multicolumn{3}{|l|}{ Marital status } \\
\hline Married/cohabiting & 205 & 64.7 \\
\hline Single/widowed/divorced & 112 & 35.3 \\
\hline \multicolumn{3}{|l|}{ Occupation } \\
\hline Economically active ${ }^{\mathrm{a}}$ & 275 & 86.8 \\
\hline Not economically active ${ }^{b}$ & 42 & 13.2 \\
\hline \multicolumn{3}{|l|}{ Age at first pregnancy (years) } \\
\hline$\leq 17$ & 27 & 8.5 \\
\hline $18-21$ & 97 & 30.6 \\
\hline $22-25$ & 76 & 24.0 \\
\hline$>25$ & 59 & 18.6 \\
\hline Never pregnant & 37 & 11.7 \\
\hline Do not remember & 21 & 6.6 \\
\hline \multicolumn{3}{|l|}{ Gravidae } \\
\hline 0 & 37 & 11.7 \\
\hline 1 & 36 & 11.4 \\
\hline$\geq 2$ & 244 & 76.9 \\
\hline \multicolumn{3}{|l|}{ Parity } \\
\hline 0 & 63 & 19.8 \\
\hline 1 & 52 & 16.4 \\
\hline $2-4$ & 162 & 51.1 \\
\hline$>5$ & 40 & 12.6 \\
\hline \multicolumn{3}{|l|}{ Age of coitarche (years) } \\
\hline$\leq 15$ & 22 & 6.9 \\
\hline $16-20$ & 171 & 53.9 \\
\hline $21-25$ & 42 & 13.2 \\
\hline$\geq 26$ & 20 & 6.3 \\
\hline Do not remember & 62 & 19.6 \\
\hline \multicolumn{3}{|l|}{ Number of life time sex partners } \\
\hline 1 & 112 & 35.3 \\
\hline $2+$ & 205 & 64.7 \\
\hline \multicolumn{3}{|l|}{ Alcohol consumption } \\
\hline Yes & 135 & 42.6 \\
\hline No & 182 & 57.4 \\
\hline \multicolumn{3}{|l|}{ Condom use } \\
\hline Yes & 108 & 34.1 \\
\hline No & 209 & 65.9 \\
\hline
\end{tabular}

SHS Senior high school

${ }^{a}$ Economically active-have any job

${ }^{\mathrm{b}}$ Not economically active-have no job, pensioner or housewife 
Table 2 Prevalence of human papilloma virus (HPV) and vaccine covered genotypes among women

\begin{tabular}{|c|c|c|c|c|c|c|c|}
\hline \multirow[t]{2}{*}{ Parameter } & \multirow[t]{2}{*}{ Frequency* } & \multirow{2}{*}{$\begin{array}{l}\text { Proportion } \\
(\%)^{\mathrm{a}}\end{array}$} & \multirow{2}{*}{$\begin{array}{l}\text { Proportion } \\
(\%)^{b}\end{array}$} & \multirow{2}{*}{$\begin{array}{l}\text { Proportion } \\
(\%)^{c}\end{array}$} & \multirow[t]{2}{*}{ SE } & \multicolumn{2}{|l|}{$95 \% \mathrm{Cl}$} \\
\hline & & & & & & Lower & Upper \\
\hline HPV positive & 138 & 43.5 & & & 2.9 & 37.9 & 48.6 \\
\hline \multicolumn{8}{|l|}{ Type of infection } \\
\hline Single & 59 & 18.6 & 42.8 & & 2.1 & 14.2 & 23.0 \\
\hline Multiple & 79 & 24.9 & 57.2 & & 2.5 & 20.2 & 30.6 \\
\hline \multicolumn{8}{|l|}{ Risk category } \\
\hline High risk & 111 & 35.0 & 80.4 & & 2.8 & 29.6 & 40.4 \\
\hline Probable high risk & 46 & 14.5 & 33.3 & & 2.0 & 10.7 & 18.3 \\
\hline Low risk & 54 & 17.0 & 39.1 & & 2.2 & 12.9 & 21.2 \\
\hline \multicolumn{8}{|l|}{ High-risk HPV genotype } \\
\hline HPV-16 & 14 & 4.4 & 10.1 & 12.6 & 1.2 & 2.2 & 6.6 \\
\hline HPV-18 & 13 & 4.1 & 9.4 & 11.7 & 1.1 & 2.2 & 6.3 \\
\hline HPV-31 & 12 & 3.8 & 8.7 & 10.8 & 1.1 & 1.9 & 6.3 \\
\hline HPV-33 & 2 & 0.6 & 1.4 & 1.8 & 0.5 & 0.0 & 1.6 \\
\hline HPV-35 & 17 & 5.4 & 12.3 & 15.3 & 1.3 & 2.8 & 7.9 \\
\hline HPV-39 & 10 & 3.2 & 7.2 & 9.0 & 1.0 & 1.6 & 5.4 \\
\hline HPV-45 & 13 & 4.1 & 9.4 & 11.7 & 1.1 & 2.2 & 6.3 \\
\hline HPV-51 & 7 & 2.2 & 5.1 & 6.3 & 0.8 & 0.6 & 3.8 \\
\hline HPV-52 & 58 & 18.3 & 42.0 & 52.3 & 2.1 & 14.2 & 22.4 \\
\hline HPV-56 & 8 & 2.5 & 5.8 & 7.2 & 0.9 & 0.9 & 4.4 \\
\hline HPV-58 & 28 & 8.8 & 20.3 & 25.2 & 1.6 & 5.7 & 12.0 \\
\hline HPV-59 & 6 & 1.9 & 4.3 & 5.4 & 0.7 & 0.6 & 3.5 \\
\hline \multicolumn{8}{|c|}{ Probable high-risk HPV genotype } \\
\hline HPV-66 & 25 & 7.9 & 18.1 & 54.3 & 1.5 & 5.3 & 11.1 \\
\hline HPV-68 & 26 & 8.2 & 18.8 & 56.5 & 1.5 & 5.7 & 11.4 \\
\hline \multicolumn{8}{|l|}{ Low-risk HPV genotype } \\
\hline HPV-6/11 & 3 & 0.9 & 2.2 & 5.6 & 0.6 & 0.0 & 2.2 \\
\hline HPV-42 & 30 & 9.5 & 21.7 & 55.6 & 1.6 & 6.3 & 12.9 \\
\hline HPV-43 & 17 & 5.4 & 12.3 & 31.5 & 1.3 & 2.8 & 8.2 \\
\hline HPV-44 & 7 & 2.2 & 5.1 & 13.0 & 0.8 & 0.6 & 3.8 \\
\hline \multicolumn{8}{|l|}{ Vaccine covered genotypes } \\
\hline HPV 16/18 & 26 & 8.2 & & & 1.6 & 5.0 & 11.7 \\
\hline HPV 6/11/16/18 & 29 & 9.1 & & & 1.7 & 6.0 & 12.6 \\
\hline $\begin{array}{l}\text { HPV } \\
6 / 11 / 16 / 18 / 31 / 33 / 45 / 52 / 58\end{array}$ & 90 & 28.4 & & & 2.5 & 23.3 & 33.2 \\
\hline
\end{tabular}

*Because of the possibility of multiple infections, women may be counted more than once

${ }^{\text {a }}$ Percentages calculated using the total number of cases $(\mathrm{N}=317)$ as a common denominator

${ }^{b}$ Percentages calculated using the number of positive cases $(\mathrm{N}=138)$ as a common denominator

' Percentages calculated using the number of positive cases among the risk category as a common denominator

2.2-6.3). Among participants positive for HPV, 42.8\% $(\mathrm{n}=59)$ were infected with single HPV type infection and $57.2 \%(\mathrm{n}=79)$ were infected with multiple HPV types.

\section{HPV vaccine type prevalence}

The prevalence of women with the bivalent vaccine type HPV (16/18) was $8.2 \%$ (95\% CI $4.7-11.4 \%$ ), quadrivalent vaccine-type HPV $(6 / 11 / 16 / 18)$ was $9.1 \%$ (95\% CI 5.7-12.3\%) and nonavalent vaccine-type HPV
(6/11/16/18/31/33/45/52/58) was $28.4 \%$ (95\% CI $23.6-$ $32.8 \%$ ) (Table 3). The overall frequency of infections caused by HR HPV genotypes, covered by three vaccines (bivalent, quadrivalent and nonavalent) was lower (28.4\%) than the overall frequency of all other HPVs detected in the study (45\%), as some of the women had multiple infection with different HPV genotypes. Prevalence of HPV-16 and HPV-18 was 4.4\% (14/317) and $4.1 \%$ (13/317), respectively. Prevalence of HPV 6/11 
Table 3 HPV genotype frequency and prevalence among single and multiple HPV infections observed in 138 positive women

\begin{tabular}{|c|c|c|c|c|c|c|c|c|c|}
\hline \multirow[t]{3}{*}{$\mathrm{S} / \mathrm{N}$} & \multirow[t]{3}{*}{ HPV category } & \multirow[t]{3}{*}{ HPV genotype } & \multicolumn{6}{|c|}{ Type of HPV infection } & \multirow[t]{3}{*}{ Total multiple } \\
\hline & & & \multirow{2}{*}{$\begin{array}{l}\text { Single infection } \\
1\end{array}$} & \multicolumn{5}{|c|}{ Multiple infection } & \\
\hline & & & & 2 & 3 & 4 & 5 & 6 & \\
\hline 1 & $H R$ & 16 & 3 & 4 & 1 & 4 & 1 & 1 & 11 \\
\hline 2 & & 18 & 8 & 2 & 0 & 1 & 2 & 0 & 5 \\
\hline 3 & & 31 & 2 & 1 & 2 & 2 & 4 & 1 & 10 \\
\hline 4 & & 33 & 0 & 2 & 1 & 0 & 0 & 0 & 2 \\
\hline 5 & & 35 & 6 & 6 & 2 & 2 & 1 & 0 & 11 \\
\hline 6 & & 39 & 1 & 2 & 1 & 3 & 3 & 0 & 9 \\
\hline 7 & & 45 & 1 & 2 & 1 & 3 & 3 & 3 & 12 \\
\hline 8 & & 51 & 0 & 2 & 0 & 3 & 2 & 0 & 7 \\
\hline 9 & & 52 & 10 & 21 & 19 & 5 & 3 & 0 & 48 \\
\hline 10 & & 56 & 3 & 2 & 2 & 1 & 0 & 0 & 5 \\
\hline 11 & & 58 & 2 & 8 & 6 & 6 & 4 & 2 & 26 \\
\hline 12 & & 59 & 0 & 2 & 2 & 1 & 0 & 1 & 6 \\
\hline 1 & PHR & 66 & 1 & 3 & 4 & 8 & 6 & 3 & 24 \\
\hline 2 & & 68 & 5 & 6 & 6 & 5 & 3 & 1 & 21 \\
\hline 1 & LR & $6 / 11$ & 0 & 1 & 0 & 1 & 0 & 1 & 3 \\
\hline 2 & & 42 & 14 & 4 & 5 & 3 & 3 & 1 & 16 \\
\hline 3 & & 43 & 1 & 11 & 4 & 0 & 1 & 0 & 16 \\
\hline 4 & & 44 & 3 & 1 & 0 & 1 & 2 & 0 & 4 \\
\hline
\end{tabular}

was $0.9 \%$ (3/317). Prevalence of additional five HPV genotypes included in nonavalent vaccine, HPV-31, 33, 45,52 and 58 were $3.8 \%(12 / 317), 0.6 \%(2 / 317), 4.1 \%$ $(13 / 317), 18.3 \%(58 / 317)$ and $8.8 \%(28 / 317)$ respectively. Table 3 shows, that among HR HPV group with single infection HPV-52 was more prevalent $(n=9)$, whereas among LR HPV group HPV-42 was more prevalent $(\mathrm{n}=14)$.

\section{Prevalence of HPV genotypes according to cervical cytology}

Among participants with normal cytology results, 43.0\% (129/300) were found to be positive for HPV infection (Table 4). Among women whose results were reported ASCUS/LSIL and HSIL/SCC, 66.7\% (4/6) and $33.3 \%$ (1/3) were HPV positive, respectively. Majority of participants with normal cytology had multiple HPV infection $(n=73)$. Among cases with abnormal cytology report, only one had single HPV infection but the majority of abnormal cytology were infected with multiple genotypes (Table 4). Among women with normal cytology results, the most prevalent HR HPV type was HPV-52 $(\mathrm{n}=55)$, followed by HPV-58 $(\mathrm{n}=27)$. However, the most common LR was HPV-42 $(n=30)$. Among abnormal cytology results the most prevalent HR HPV type was also HPV-52 $(n=3)$, followed by
HPV-45 $(\mathrm{n}=2)$ and HPV-35 $(\mathrm{n}=2)$. Nonavalent vaccine HPV genotypes were found among 50\% (3/6) cases with ASCUS/LSIL and 33.3\% (1/3) cases with HSIL/ SCC.

\section{Associated risk factors}

The results were further analyzed for cross-sectional associations between infection with HPV and sociodemographic, obstetric and behavioral characteristics, as well as the development of squamous intraepithelial lesions (Tables 5 and 6). Potentially significant associations were observed between infection with HPV and educational background $(p<0.001)$, age of first sexual intercourse $(p=0.016)$ and age of first pregnancy $(p=0.028)$.

\section{Discussion}

Epidemiological data on circulating type-specific HPV prevalence in a population is a very important rationale for introducing HPV vaccines and can provide an early measure of vaccine impact. In particular, it is important in countries where organized screening programs for the prevention of cervical cancer have not yet been established at scale. We conducted a multicenter descriptive study of the prevalence of HPV infection, and the vaccine-related genotype distribution among 
Table 4 Prevalence of HPV infection and HPV genotype distribution in cytology outcome among participants

\begin{tabular}{llll}
\hline Parameter & \multicolumn{4}{l}{ Cytology results } \\
\cline { 2 - 5 } & Normal, $n \quad \begin{array}{l}\text { ASCUS/ } \\
\text { LSIL, } n\end{array}$ & HSIL/SCC, $n$ & $\begin{array}{l}\text { Unsatisfactory, } \\
n\end{array}$ \\
& &
\end{tabular}

\begin{tabular}{lccll}
\hline \multicolumn{2}{l}{ Type of infection } & & & \\
Single & 56 & 1 & 0 & 2 \\
Multiple & 73 & 3 & 1 & 2 \\
HPV genotype & & & & \\
High-risk & & & & \\
HPV 16 & 10 & 0 & 1 & 3 \\
HPV 18 & 13 & 0 & 0 & 0 \\
HPV 31 & 10 & 1 & 0 & 1 \\
HPV 33 & 0 & 1 & 0 & 1 \\
HPV 35 & 15 & 2 & 0 & 0 \\
HPV 39 & 9 & 0 & 1 & 0 \\
HPV 45 & 11 & 2 & 0 & 0 \\
HPV 51 & 7 & 0 & 0 & 0 \\
HPV 52 & 55 & 3 & 1 & 0 \\
HPV 56 & 7 & 0 & 0 & 1 \\
HPV 58 & 27 & 0 & 1 & 0 \\
HPV 59 & 6 & 0 & 0 & 0 \\
Probable high-risk & & & \\
HPV 66 & 24 & 1 & 0 & 0 \\
HPV 68 & 25 & 0 & 0 & 1 \\
Low-risk & & & 0 \\
HPV 6/11 & 3 & 0 & 0 & 0 \\
HPV 42 & 30 & 0 & 0 & \\
HPV 43 & 17 & 0 & 0 & 0 \\
HPV 44 & 7 & 0 & 0 & \\
\hline
\end{tabular}

women presenting to reproductive health clinics. The prevalence of HPV infection detected in this study was $43.5 \%$ (95\% CI 37.9-48.6). A similarly high prevalence of HPV in women in Sub-Saharan Africa has been reported by a number of studies [38-41]. A previous study done at the antenatal clinic in Korle-Bu Teaching Hospital among 93 healthy pregnant women reported HPV infection prevalence of $64.5 \%(n=60)$ [42]. Yar and colleagues reported an overall HPV positivity for HIV-positive women and a control group as $86.9 \%$ and $56.0 \%$ respectively (for both case and control overall HPV prevalence was 72.0\%) [40]. In general, differences in HPV prevalence reports may also be explained by the differences in study methodology: more specifically, the case volumes, the type of the case groups, study population and the method employed for HPV detection [43]. The present study relies on a highly-sensitive nested multiplex PCR (NMPCR) assay that combines degenerate E6/E7 consensus primers and type-specific primers for $16 \mathrm{HPV}$ genotypes. This assay has been tried and proven to give consistent and reliable results when followed [37] and has been used in a couple of studies in Sub-Saharan Africa [34, 42, 44]. Polymerase chain reaction-based assays showed HPV prevalence of $40 \%$ in rural Mozambique [41], 31\% in Harare, Zimbabwe [45], and $44 \%$ in Nairobi, Kenya. These figures suggest similar endemicity of HPV infection in the region.

Higher HPV prevalence may also be attributed to the nature of the study population and age range. Women of reproductive age may be more sexually active than women of other age-groups such as adolescent girls and elderly women. Available epidemiological data on HPV in high-risk population groups promote the idea that overrepresentation of high-risk women in general population studies may raise the observed prevalence. For instance, among HIV-positive and HIV-negative women recruited at the Cape-Coast Teaching Hospital, prevalence of HPV infection was reported as $75 \%$ and $42.6 \%$, respectively [46]. In addition, HIV-positive women have higher rates of persistent HPV infections [40, 46].

Infection with more than a single genotype is a common feature of HPV infections [3, 47]. Cervical coinfection with multiple HPV types was observed for both HR HPV and LR HPV infections, and was supported by previous studies in Ghana [40, 42, 48] and sub-Saharan Africa $[39,49,50]$. Although co-infection of HPV genotypes occurs very frequently, the evidence suggests that the presence of multiple types does not especially influence clearance of HPV infections either by natural mechanism or vaccine-induced immunity [51, 52]. Rather, multiple infections occur as independent events sharing common transmission routes and having a similar profile of risk factors [53].

The more common HPV genotypes, from HR-HPV and PHR-HPV groups, identified among the study participants were HPV-52, HPV-58, HPV-66, HPV-68 and 35. In one Ghanaian study, Yar et al. [40] reported five predominant HR-HPV genotypes 58, 35, 68, 31 and 18, whereas Brandful et al. [42] reported 68, 66, 58, 35 and 56. Awua et al. [44], reported HP-16 (5.9\%), HPV-35 (4.7\%), HPV-40 (4.7\%), HPV-45 (4.3\%), HPV-58 (4.0\%), HPV-18 (3.6\%) to be the most prevalent HPV genotypes detected in self-collected specimens. Krings et al. [54] at North Tongu District of Ghana reported top five HPV genotypes: 16 (7.4\%), 52 (7.2\%), 35 (4.8\%, 59 (4.7\%) and $56(3.9 \%)$. Concordance between studies on the distributions of observed genotypes strengthen our results and the conclusions that emanate from this work.

Additionally, the prevalence of HPV-16 and HPV-18 was $4.4 \%$ and $4.1 \%$ respectively. The higher prevalence of HPV-18 over HPV-16 in this study is similar to previous reports among available local studies in normal cervixes $[40,42,55]$ and cancerous tissue $[44,56]$. Although the 
Table 5 Crude odds ratio on the association between socio-demographic and obstetric characteristics and HPV positivity

\begin{tabular}{|c|c|c|c|c|c|}
\hline Parameter & n (\%) & $\mathrm{X}^{2}$ ( $p$ value $)$ & B ( $p$ value) & OR & $95 \% \mathrm{Cl}$ \\
\hline \multicolumn{6}{|c|}{ Demographic characteristics } \\
\hline Age group, years & & $4.283(0.232)$ & & & \\
\hline$\leq 25$ & $8(2.5)$ & & & 1 & \\
\hline $25-44$ & $215(67.8)$ & & $-1.332(0.108)$ & 0.264 & $0.052-1.337$ \\
\hline $45-64$ & $87(27.4)$ & & $-1.495(0.077)$ & 0.224 & $0.043-1.176$ \\
\hline$\geq 65$ & $7(2.2)$ & & $-2.015(0.085)$ & 0.133 & $0.013-1.318$ \\
\hline Education & & $18.878(\mathbf{0 . 0 0 0})$ & & & \\
\hline$<\mathrm{SHS}$ & $188(59.3)$ & & & 1 & \\
\hline$\geq \mathrm{SHS}$ & $129(40.7)$ & & $1.014(\mathbf{0 . 0 0 0})$ & 2.756 & $1.735-4.377$ \\
\hline Marital status & & $0.003(0.954)$ & & & \\
\hline Married/cohabiting & $205(64.7)$ & & $-0.014(0.954)$ & 0.986 & $0.620-1.569$ \\
\hline Single/widowed/divorced & $112(35.3)$ & & & 1 & \\
\hline Occupation & & $3.117(0.077)$ & & & \\
\hline Economically active $^{a}$ & $275(86.8)$ & & $0.620(0.081)$ & 1.859 & $0.927-3.728$ \\
\hline Not economically active ${ }^{b}$ & $42(13.2)$ & & & 1 & \\
\hline \multicolumn{6}{|l|}{ Obstetric characteristics } \\
\hline Age at first pregnancy (years) & $12.508(\mathbf{0 . 0 2 8})$ & & & & \\
\hline$\leq 17$ & $27(8.5)$ & & & 1 & \\
\hline $18-21$ & 97 (30.6) & & $1.605(\mathbf{0 . 0 0 6})$ & 4.976 & $1.601-15.470$ \\
\hline $22-25$ & $76(24.0)$ & & $1.377(\mathbf{0 . 0 2 0})$ & 3.961 & $1.247-12.587$ \\
\hline$>25$ & 59 (18.6) & & $1.579(\mathbf{0 . 0 0 9})$ & 4.852 & $1.492-15.771$ \\
\hline Never pregnant & $37(11.7)$ & & $2.021(\mathbf{0 . 0 0 1})$ & 7.547 & $2.173-26.214$ \\
\hline Do not remember & $21(6.6)$ & & $1.654(\mathbf{0 . 0 1 7})$ & 5.227 & $1.336-20.450$ \\
\hline Gravidae & & $4.114(0.128)$ & & & \\
\hline 0 & $37(11.7)$ & & & 1 & \\
\hline 1 & $36(11.4)$ & & $-0.272(0.563)$ & 0.762 & $0.303-1.915$ \\
\hline$\geq 2$ & $244(77.0)$ & & $-0.654(0.067)$ & 0.520 & $0.259-1.046$ \\
\hline Parity & & $3.653(0.301)$ & & & \\
\hline 0 & $63(19.9)$ & & & 1 & \\
\hline 1 & $52(16.4)$ & & $-0.438(0.249)$ & 0.645 & $0.306-1.360$ \\
\hline $2-4$ & $162(51.1)$ & & $-0.142(0.634)$ & 0.868 & $0.485-1.555$ \\
\hline$>5$ & 40 (12.6) & & $-0.699(0.097)$ & 0.497 & $0.218-1.135$ \\
\hline
\end{tabular}

Bold font: $p$ value $<0.05$

${ }^{a}$ Economically active-engages in paid work

${ }^{\mathrm{b}}$ Not economically active-has no paid work, pensioner or housewife

proportions of specific genotypes differ, similar reports confirm that the most common genotypes detected in this study are equally prominent across other African countries both in women with normal cytology and in those with HSIL or worse [38, 41, 45, 49, 57]. It is possible that local differences in HPV distributions actually exist and must be continuously investigated in order to better understand the complex interplay of factors that shape HPV distributions in populations. However, it is also plausible that type-specific HPV prevalence may be influenced by the type of assay used and by the preponderance of multiple HPV infection in certain populations [45].

An important question which population HPV studies seek to answer pertains to the frequency of detection of HPV-16 and-18, the two most common high-risk genotypes prevented by available vaccines. The combined prevalence of HPV-16 and 18 in this study is similar to estimates from other local studies from Kumasi (6.2\%) [32] and Accra (6.6\%) [42]. The result of this study is consistent with other studies, which reported lower prevalence of these two vaccine-preventable genotypes 
Table 6 Crude odds ratio on the association between behavioral characteristics and HPV positivity

\begin{tabular}{|c|c|c|c|c|c|}
\hline Parameter & n (\%) & $X^{2}$ ( $p$ value) & B ( $p$ value) & OR & $95 \% \mathrm{Cl}$ \\
\hline Age of coitarche (years) & $12.130(\mathbf{0 . 0 1 6})$ & & & & \\
\hline$\leq 15$ & $22(6.9)$ & & & 1 & \\
\hline $16-20$ & $171(53.9)$ & & $1.503(\mathbf{0 . 0 1 9})$ & 4.497 & $1.282-15.775$ \\
\hline $21-25$ & $42(13.2)$ & & $1.751(\mathbf{0 . 0 1 2})$ & 5.758 & $1.478-22.431$ \\
\hline$\geq 26$ & $20(6.3)$ & & $1.846(\mathbf{0 . 0 1 6})$ & 6.333 & $1.413-28.393$ \\
\hline Do not remember & $62(19.6)$ & & $2.040(\mathbf{0 . 0 0 2})$ & 7.690 & $2.062-28.665$ \\
\hline Number of life time sex partners & $0.032(0.858)$ & & & & \\
\hline 1 & $112(35.3)$ & & & 1 & \\
\hline $2+$ & $205(64.7)$ & & $0.043(0.858)$ & 1.043 & $0.656-1.661$ \\
\hline Tobacco use & & $0.069(0.793)$ & & & \\
\hline Yes & $4(1.3)$ & & $0.184(0.857)$ & 1.201 & $0.162-8.895$ \\
\hline No & $313(98.7)$ & & & 1 & \\
\hline Alcohol consumption & $2.037(0.153)$ & & & & \\
\hline Yes & $135(42.6)$ & & $0.280(0.236)$ & 1.323 & $0.833-2.101$ \\
\hline No & $182(57.4)$ & & & 1 & \\
\hline Condom use & & $1.419(0.234)$ & & & \\
\hline Yes & $108(34.1)$ & & & 1 & \\
\hline No & $209(65.9)$ & & $-2.333(0.340)$ & 0.792 & $0.490-1.279$ \\
\hline
\end{tabular}

Bold font: $p$ value $<0.05$

in the general population compared to studies involving histologically confirmed cancer tissue [58-60]. These findings support the knowledge that HPV16 and HPV18 are mostly under-represented in women with normal cytology by comparison with their importance in severe cervical lesions and underscore their epidemiological reputation as more aggressive carcinogenic agents and justify the use of preventive vaccination in cancer prevention $[5,61,62]$.

Since 2015, the Advisory Committee on Immunization Practices (ACIP) recommended an FDA approved nonavalent (9-valent) human papillomavirus (HPV) vaccine (9vHPV) (Gardasil 9, Merck and Co., Inc.) containing HPV-31, 33, 45, 52, and 58 VLPs in addition to the quadrivalent vaccine coverage $[17,18]$. This new vaccine is hoped to expand the range of existing vaccines and protect even more women from HPV infections. Gardasil 9 vaccine includes five more HPV genotypes (HPV52, 58, 45, and 31) covering the most common HR-HPV types found in our study among Ghanaian women. The high prevalence of nonavalent vaccine-preventable types coincidental with abnormal cytological findings taken together with previous reports of the distribution of vaccine preventable HPV genotypes in malignant cervical tissue $[56,58]$ show that expanded genotype vaccines may be more beneficial than previous vaccines in this population.

Earlier age at sexual debut puts women at greater risk for HPV infection [63]. An association between young age and cervical HPV infections is generally attributed to a higher susceptibility to the infection at the beginning of sexual activity, with peak prevalence in younger women and progressive decline with increasing age [64].

In this study we found that although there was a high burden of HPV infection in young adult women (18-25 years) (Additional file 1), the overall prevalence of infection from vaccine-type HPVs in sexually active women was low in the age group less than 25 years $(0 \%$ for HPV-16/18, 0\% for HPV-6/11/16/18 and $1.3 \%(4 / 318)$ for HPV-6/11/16/18/31/33/45/53/58) and a wide margin of interventions with vaccine primary prophylaxis beyond the preadolescent girls aged 9-12 years, who are actually the target for vaccine, could be expected.

In this work, an important socio-demographical risk factor associated with of HPV DNA infection was education. In general, low educational status is thought to indicate poor knowledge and compliance for safer sexual behavior; including number of sex partners and use of protective condoms [65]. Our results suggest that higher education may not necessarily be indicative of knowledge of HPV or safer sexual behavior. Our data showed that women who were active (have any job, government or private) had 2 times higher risk to be infected with HPV, than those who were not active (do not have any job). But our study did not look at the association of prevalence of HPV infection with socio-economic status of the women. Though this contradiction would be hard to explain, it 
may be related to difference in a risk behavior correlated with education.

\section{Limitations}

The study used a convenient hospital-based sampling. The benefits of this approach include time and costsavings. However, there are many setbacks with this approach to sampling. These include a high chance of bias and the applicability of findings to other population groups such as community-dwelling women or the general population of women. Bias was minimized by excluding previously screened women and skipping every third woman presenting to the clinic. These factors should always be borne in mind when interpreting study results.

\section{Conclusion}

Vaccine preventable high-risk HPV types represent 8.2\% (HPV-16 and 18) and 9.1\% (HPV-6, 11, 16 and 18) of the burden of HPV infections in the population studied. Although the impact of universal vaccination with existing vaccines would be much greater with data from women with pre-cancerous lesions, our data shows that the nonavalent vaccine targeted at HR HPV-16, -18, -31, $-33,-45,-52$ and -58 , would cover $28.40 \%$ of HPV infections. As the country prepares to achieve $90 \%$ universal vaccine coverage, the role of expanded-scope vaccines that confer immunity against region-specific oncogenic HPV types can be essential. It is an urgent need to introduce the nonavalent vaccine to the country at scale.

\footnotetext{
Abbreviations

ASCUS: Atypical squamous cells of undetermined significance; GAVl: Global alliance for vaccines initiative; HPV: Human papillomavirus; HR-HPV: High risk human papillomavirus; HSIL: High grade squamous intraepithelial lesion; ICC: Invasive cervical cancer; LR-HPV: Low risk human papillomavirus; LSIL: Lowgrade squamous intraepithelial lesion; PHR-HPV: Probable high risk human papillomavirus; Pap: Papanicolaou; SPSS: Statistical package for the social scientists; SCC: Squamous cervical cancer; VIA: Visual inspection with acetic acid; WHO: World health organization.
}

\section{Supplementary Information}

The online version contains supplementary material available at https://doi. org/10.1186/s12905-021-01511-1.

Additional file 1. Prevalence of vaccine-preventable human papillomaviruses stratified according to demographic and reproductive characteristics.

\section{Acknowledgements}

We wish to acknowledge all the staff of Cervicare centers from both facilities (Accra and Kumasi) in Ghana and all the study participants.

\section{Authors' contributions}

OD and ETD formulated the concept, carried out the implementation of the research, recruited study participants, performed laboratory analysis, analyzed and interpreted the data, wrote the manuscript with input from all authors. FAY refined the concept, directed the implementation of research, supervised findings of this work, and was a major contributor in writing the manuscript and final approval of the version to be published. RHA developed all laboratory protocols, directed the implementation of research, helped to supervise the project and approved the final version of the manuscript. All authors read and approved the final manuscript

\section{Funding}

The research was funded by the authors.

\section{Availability of data and materials}

The dataset supporting the conclusions of this article is included within the article and its additional files. More detailed data can be obtained from the Committee on Human Research Publication and Ethics (CHRPE), Kwame Nkrumah University of Science and Technology, School of Medical Sciences (KNUST-SMS) and Komfo Anokye Teaching Hospital (KATH) board.

\section{Declarations}

\section{Ethical approval and consent to participate}

All methods were carried out in accordance with relevant guidelines and regulations. The study was approved by the Committee on Human Research Publication and Ethics (CHRPE), Kwame Nkrumah University of Science and Technology, School of Medical Sciences (KNUST-SMS) and Komfo Anokye Teaching Hospital (KATH) (CHRPE/AP/115/14), Kumasi, Ghana and Ghana Health Service Ethical Review Committee, Research and Development Division (GHS-ERC:07/03/14). Voluntary written informed consent was obtained from the participants. The study was conducted in an environment with no form of coercion and volunteers were adequately informed of the purpose, nature and procedures of the study.

\section{Consent for publication}

Not applicable.

\section{Competing interests}

The authors declare that they have no competing interests.

\section{Author details}

${ }^{1}$ Institutional Care Division, Ghana Health Service Headquarters, Stadium Post Office, Post Office Box SD 329, Accra, Ghana. ${ }^{2}$ Department of Molecular Medicine, Kwame Nkrumah University of Science and Technology, Kumasi, Ghana. ${ }^{3}$ Department of Basic and Applied Biology, University of Energy and Natural Resources, Sunyani, Ghana. ${ }^{4}$ University of Health and Allied Sciences, Ho, Ghana. ${ }^{5}$ Department of Science Laboratory Technology, Accra Technical University, Accra, Ghana.

Received: 22 January 2021 Accepted: 11 October 2021 Published online: 26 October 2021

References

1. Forman D, de Martel C, Lacey CJ, Soerjomataram I, Lortet-Tieulent J, Bruni $L$, et al. Global burden of human papillomavirus and related diseases. Vaccine. 2012;30(Suppl 5):F12-23.

2. Doorbar J, Egawa N, Griffin H, Kranjec C, Murakami I. Human papillomavirus molecular biology and disease association. Rev Med Virol. 2015:25:2-23

3. Clifford G, Gallus S, Herrero R, Munoz N, Snijders P, Vaccarella S, et al. Worldwide distribution of human papillomavirus types in cytologically normal women in the International Agency for Research on Cancer HPV prevalence surveys: a pooled analysis. The Lancet. 2005;366(9490):991-8.

4. De Vuyst H, Alemany L, Lacey C, Chibwesha CJ, Sahasrabuddhe V, Banura

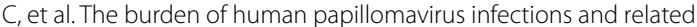
diseases in sub-Saharan Africa. Vaccine. 2013;31(05):F32-46. 
5. Muñoz N, Bosch FX, Castellsagué X, Díaz M, de Sanjose S, Hammouda D, et al. Against which human papillomavirus types shall we vaccinate and screen? The international perspective. Int J Cancer. 2004;111(2):278-85.

6. Denny L, Adewole I, Anorlu R, Dreyer G, Moodley M, Smith T, et al. Human papillomavirus prevalence and type distribution in invasive cervical cancer in sub-Saharan Africa. Int J Cancer. 2014;134(6):1389-98.

7. Sung H, Ferlay J, Siegel RL, Laversanne M, Soerjomataram I, Jemal A, et al. Global cancer statistics 2020: GLOBOCAN estimates of incidence and mortality worldwide for 36 cancers in 185 countries. CA Cancer J Clin. 2021;71(3):209-49.

8. Amoako YA, Awuah B, Larsen-Reindorf R, Awittor FK, Kyem G, Ofori-Boadu $\mathrm{K}$, et al. Malignant tumours in urban Ghana: evidence from the city of Kumasi. BMC Cancer. 2019;19(1):267.

9. WHO/ICO. Human Papillomavirus and Related Disease Report. Ghana. in WHO Information Center o HPV and Cancer. 2016.

10. Paz-Zulueta M, Álvarez-Paredes L, Díaz JCR, Parás-Bravo P, Becerra MEA, Ingelmo JMR, et al. Prevalence of high-risk HPV genotypes, categorised by their quadrivalent and nine-valent HPV vaccination coverage, and the genotype association with high-grade lesions. BMC Cancer. 2018:18(1):1-9.

11. Lees BF, Erickson BK, Huh WK. Cervical cancer screening: evidence behind the guidelines. J Am J Obst Gynecol. 2016;214(4):438-43.

12. Olesen SC, Butterworth P, Jacomb P, Tait RJ. Personal factors influence use of cervical cancer screening services: epidemiological survey and linked administrative data address the limitations of previous research. BMC Health Serv Res. 2012;12(1):1-9.

13. Wright TC Jr, Kuhn L. Alternative approaches to cervical cancer screening for developing countries. Best Pract Res Clin Obst Gynaecol. 2012;26(2):197-208.

14. Fokom-Domgue J, Combescure C, Fokom-Defo V, Tebeu PM, Vassilakos $\mathrm{P}$, Kengne AP, et al. Performance of alternative strategies for primary cervical cancer screening in sub-Saharan Africa: systematic review and meta-analysis of diagnostic test accuracy studies. BMJ. 2015. https:// doi.org/10.1136/bmj.h3084

15. Kreimer AR, Gonzalez P, Katki HA, Porras C, Schiffman M, Rodriguez AC, et al. Efficacy of a bivalent HPV 16/18 vaccine against anal HPV 16/18 infection among young women: a nested analysis within the Costa Rica Vaccine Trial. Lancet Oncol. 2011;12(9):862-70.

16. Maclntyre CR, Shaw P, Mackie FE, Boros C, Marshall H, Barnes M, et al. Immunogenicity and persistence of immunity of a quadrivalent Human Papillomavirus (HPV) vaccine in immunocompromised children. Vaccine. 2016;34(36):4343-50

17. Petrosky E, Bocchini J Jr, Hariri S, Chesson H, Curtis C, Saraiya M, et al. Use of 9-valent human papillomavirus (HPV) vaccine: updated HPV vaccination recommendations of the advisory committee on immunization practices. MMWR Morb Mortal Wkly Rep. 2015;64(11):300.

18. FDA. Approval letter-GARDASIL 9. Silver Spring, MD: Food and Drug Administration; 2014

19. Kemp TJ, Safaeian M, Hildesheim A, Pan Y, Penrose KJ, Porras C, et al. Kinetic and HPV infection effects on cross-type neutralizing antibody and avidity responses induced by Cervarix ${ }^{\circledR}$. Vaccine. 2012;31(1):165-70.

20. Safaeian M, Kemp TJ, Pan DY, Porras C, Rodriguez AC, Schiffman M, et al. Cross-protective vaccine efficacy of the bivalent HPV vaccine against HPV31 is associated with humoral immune responses: results from the Costa Rica Vaccine Trial. Hum Vaccin Immunother. 2013;9(7):1399-406.

21. LaMontagne DS, Mugisha E, Pan Y, Kumakech E, Ssemaganda A, Kemp TJ, et al. Immunogenicity of bivalent HPV vaccine among partially vaccinated young adolescent girls in Uganda. Vaccine. 2014:32(47):6303-11.

22. Levin MJ, Moscicki A-B, Song L-Y, Fenton T, Meyer WA III, Read JS, et al. Safety and immunogenicity of a quadrivalent human papillomavirus (types $6,11,16$, and 18) vaccine in HIV-infected children 7 to 12 years old. J Acq Immune Def Syndr. 2010;55(2):197.

23. Godi A, Panwar K, Haque M, Cocuzza CE, Andrews N, Southern J, et al. Durability of the neutralizing antibody response to vaccine and nonvaccine HPV types 7 years following immunization with either Cervarix ${ }^{\circledR}$ or Gardasi ${ }^{\circledR}$ vaccine. Vaccine. 2019;37(18):2455-62.

24. Expanded Programme on Immunization (EPI)/GHS. GAVI HPV Demonstration Vaccination in Ghana: Report on phase one vaccinations. Accra: GHS; 2014 November.
25. Ebu NI, Abotsi-Foli GE, Gakpo DF. Nurses' and midwives'knowledge, attitudes, and acceptance regarding human papillomavirus vaccination in Ghana: a cross-sectional study. J BMC Nurs. 2021;20(1):1-10.

26. Perlman S, Wamai RG, Bain PA, Welty T, Welty E, Ogembo JG. Knowledge and awareness of HPV vaccine and acceptability to vaccinate in subSaharan Africa: a systematic review. J PLoS ONE. 2014;9(3):e90912.

27. GHS. Adolescent Health Service Policy and Strategy 2016-2020. In: Program AHD, editor. Accra: Ghana Health Service; 2015.

28. Asare M, Agyei-Baffour P, Lanning BA, Barimah Owusu A, Commeh $M E$, Boozer K, et al. Multi-theory model and predictors of likelihood of accepting the series of HPV vaccination: a cross-sectional study among Ghanaian adolescents. J Int J Environ Res. 2020;17(2):571.

29. Palmer J, Carrico C, Costanzo C. Identifying and overcoming perceived barriers of providers towards HPV vaccination: a literature review. J Vac. 2015. https://doi.org/10.1155/2015/869468.

30. Botwright S, Holroyd T, Nanda S, Bloem P, Griffiths UK, Sidibe A, et al. Experiences of operational costs of HPV vaccine delivery strategies in Gavi-supported demonstration projects. PLOS ONE. 2017;12(10):e0182663.

31. Cochran WG. Sampling techniques. Hoboken: Wiley; 2007.

32. Donkoh E. Distribution of Genital Human Papillomaviruses and Associated Cervical Disease in Kumasi. Kumasi: Kwame Nkrumah University of Science and Technology; 2015.

33. Asare BY-A, Aryee SE, Kotoh AM. Sexual behaviour and the utilization of youth friendly health services: a cross-sectional study among urban youth in Ghana. J Int J Afr Nurs Sci. 2020;13:100250.

34. Donkoh ET, Agyemang-Yeboah F, Asmah RH, Wiredu EK. Prevalence of cervical cancer and pre-cancerous lesions among unscreened Women in Kumasi, Ghana. Medicine. 2019:98(13):e14600.

35. Massad LS, Einstein MH, Huh WK, Katki HA, Kinney WK, Schiffman M, et al. 2012 updated consensus guidelines for the management of abnormal cervical cancer screening tests and cancer precursors. J Lower Genital Tract Dis. 2013:17:S1-27.

36. de Roda Husman AM, Walboomers JM, van den Brule AJ, Meijer CJ, Snijders PJ. The use of general primers GP5 and GP6 elongated at their 3' ends with adjacent highly conserved sequences improves human papillomavirus detection by PCR. J Gen Virol. 1995;76(Pt 4):1057-62.

37. Sotlar K, Diemer D, Dethleffs A, Hack Y, Stubner A, Vollmer N. Detection and typing of human papillomavirus by e6 nested multiplex PCR. J Clin Microbiol. 2004;42(7):3176-84.

38. Xi LF, Toure P, Critchlow CW, Hawes SE, Dembele B, Sow PS, et al. Prevalence of specific types of human papillomavirus and cervical squamous intraepithelial lesions in consecutive, previously unscreened, West-African women over 35 years of age. Int J Cancer. 2003;103(6):803-9.

39. Thomas JO, Herrero R, Omigbodun AA, Ojemakinde K, Ajayi IO, Fawole A, et al. Prevalence of papillomavirus infection in women in Ibadan, Nigeria: a population based study. Br J Cancer. 2004;90:638-45.

40. Yar DD, Salifu SP, Darko SN, Annan AA, Gyimah AA, Buabeng KO, et al. Genotypic characterisation of human papillomavirus infections among persons living with HIV infection; a case-control study in Kumasi, Ghana. Trop Med Int Health. 2016;21(2):275-82.

41. Castellsague X, Menendez C, Loscertales MP, Kornegay JR, dos Santos F, Gomez-Olive FX, et al. Human papillomavirus genotypes in rural Mozambique. The Lancet. 2001;358(9291):1429-30.

42. Brandful J, Bonney E, Asmah R, Apea-Kubi K. Oncogenic human papillomavirus (HPV) in women from Ghana. J Cancer Res Exp Oncol. 2014:6(4):31-8

43. Franceschi S, Herrero R, Clifford GM, Snijders PJ, Arslan A, Anh PT, et al. Variations in the age-specific curves of human papillomavirus prevalence in women worldwide. Int J Cancer. 2006;119(11):2677-84.

44. Awua A, Sackey S, Osei Y, Asmah R, Wiredu E. Prevalence of human papillomavirus genotypes among women with cervical cancer in Ghana. Infect Agents Cancer. 2016;11(1):1.

45. Gravitt PE, Kamath AM, Gaffikin L, Chirenje ZM, Womack S, Shah KV. Human papillomavirus genotype prevalence in high-grade squamous intraepithelial lesions and colposcopically normal women from Zimbabwe. Int J Cancer. 2002;100(6):729-32.

46. Obiri-Yeboah D, Akakpo PK, Mutocheluh M, Adjei-Danso E, Allornuvor G, Amoako-Sakyi D, et al. Epidemiology of cervical human papillomavirus (HPV) infection and squamous intraepithelial lesions (SIL) among a 
cohort of HIV-infected and uninfected Ghanaian women. BMC Cancer 2017;17(1):1-10

47. Liaw KL, Hildesheim A, Burk RD, Gravitt P, Wacholder S, Manos MM, et al. A prospective study of human papillomavirus (HPV) type 16 DNA detection by polymerase chain reaction and its association with acquisition and persistence of other HPV types. J Infect Dis. 2001;183(1):8-15.

48. Adams AR, Nortey PA, Dortey BA, Asmah RH, Wiredu EK. Cervical human papillomavirus prevalence, genotypes, and associated risk factors among female sex workers in greater Accra, Ghana. J Oncol. 2019. https://doi. org/10.1155/2019/8062176.

49. Ardhaoui M, Ennaifer E, Letaief H, Salsabil R, Lassili T, Chahed K, et al. Prevalence, genotype distribution and risk factors for cervical human papillomavirus infection in the Grand Tunis Region, Tunisia. PLoS ONE. 2016;11(6):e0157432. https://doi.org/10.1371/journal.pone.0157432.

50. Gebremariam T. Human papillomavirus related cervical cancer and anticipated vaccination challenges in Ethiopia. Int J Health Sci. 2016;10(1):137-43.

51. Molano M, Van den Brule A, Plummer M, Weiderpass E, Posso H, Arslan $A$, et al. Determinants of clearance of human papillomavirus infections in Colombian women with normal cytology: a population-based, 5-year follow-up study. Am J Epidemiol. 2003;158(5):486-94.

52. Plummer M, Schiffman M, Castle PE, Maucort-Boulch D, Wheeler CM. A 2-year prospective study of human papillomavirus persistence among women with a cytological diagnosis of atypical squamous cells of undetermined significance or low-grade squamous intraepithelial lesion. J Infect Dis. 2007;195(11):1582-9.

53. Méndez F, Muñoz N, Posso H, Molano M, Moreno V, van den Brule AJ, et al. Cervical coinfection with human papillomavirus (HPV) types and possible implications for the prevention of cervical cancer by HPV vaccines. J Infect Dis. 2005;192(7):1158-65.

54. Krings A, Boateng G, Dunyo P, Amuah JE, Adams RA, Adunyame L, et al. Dynamics of genotype-specific HPV clearance and reinfection in rural Ghana may compromise HPV screening approaches. Papillomavirus Res. 2019;7:45-51.

55. Awua AK, Severini A, Wiredu EK, Afari EA, Zubach VA, Adanu RM. Selfcollected specimens revealed a higher vaccine-and non-vaccine-type human papillomavirus prevalences in a cross-sectional study in akuse. J Adv Prevent Med. 2020.

56. Attoh S, Asmah R, Wiredu EK, Gyasi R, Tetteh Y. Human Papillomavirus Genotypes in Ghanaian Women with Cervical Carcinoma. East Afr Med J. 2010;87(8):4-8.
57. De Vuyst H, Steyaert S, Van Renterghem L, Claeys P, Muchiri L, Sitati S, et al. Distribution of human papillomavirus in a family planning population in Nairobi, Kenya. Sex Trans Dis. 2003;30(2):137-42.

58. Denny L, Adewole I, Anorlu R, Dreyer G, Moodley M, Smith T. Human papillomavirus prevalence and type distribution in invasive cervical cancer in sub-Saharan Africa: cervical cancer in sub-Saharan Africa. Int J Cancer. 2014;134(6):1389-98. https://doi.org/10.1002/ijc.28425.

59. Bosch FX, De Sanjosé S. Human papillomavirus and cervical cancer-burden and assessment of causality. J Natl Cancer Inst Monogr. 2002:31:3-13.

60. de Sanjose S, Diaz M, Castellsague X, Clifford G, Bruni L, Munoz N, et al. Worldwide prevalence and genotype distribution of cervical human papillomavirus DNA in women with normal cytology: a meta-analysis. The Lancet Infect Dis. 2007;7(7):453-9.

61. Kavanagh K, Pollock KG, Potts A, Love J, Cuschieri K, Cubie H, et al. Introduction and sustained high coverage of the HPV bivalent vaccine leads to a reduction in prevalence of HPV 16/18 and closely related HPV types. Br J Cancer. 2014;110(11):2804-11.

62. Nakalembe M, Banura C, Namuiju PB, Mirembe FM. The levels of antiHPV16/18 and anti-HPV31/33/35/45/52/58 antibodies among AS04adjuvanted HPV16/18 vaccinated and non-vaccinated Ugandan girls aged 10-16 years. Infect Agent Cancer. 2014;9:29.

63. Banura C, Mirembe FM, Katahoire AR, Namujju PB, Mbonye AK, Wabwire FM. Epidemiology of HPV genotypes in Uganda and the role of the current preventive vaccines: a systematic review. Infect Agents Cancer. 2011;6(1):11.

64. Orlando G, Fasolo M, Mazza F, Ricci E, Esposito S, Frati E, et al. Risk of cervical HPV infection and prevalence of vaccine-type and other high-risk HPV types among sexually active teens and young women (13-26 years) enrolled in the VALHIDATE study. J Hum Vacc Immunother. 2014;10(4):986-94.

65. Domfeh A, Wiredu E, Adjei A, Ayeh-Kumi P, Adiku T, Tettey Y, et al. Cervical human papillomavirus infection in Accra, Ghana. Ghana Med J. 2008:42(2):71-8. https://doi.org/10.4314/gmj.v42i2.43596.

\section{Publisher's Note}

Springer Nature remains neutral with regard to jurisdictional claims in published maps and institutional affiliations.
Ready to submit your research? Choose BMC and benefit from:

- fast, convenient online submission

- thorough peer review by experienced researchers in your field

- rapid publication on acceptance

- support for research data, including large and complex data types

- gold Open Access which fosters wider collaboration and increased citations

- maximum visibility for your research: over $100 \mathrm{M}$ website views per year

At BMC, research is always in progress.

Learn more biomedcentral.com/submissions 